\title{
Summer School Versus Term-time for Fundamental Mathematics at the Tertiary Level
}

\author{
David Easdown ${ }^{\mathrm{a}}$, George Papadopoulos ${ }^{\mathrm{a}}$ and Collin Zheng $^{\mathrm{a}}$ \\ Corresponding author: David Easdown (david.easdown@sydney.edu.au)

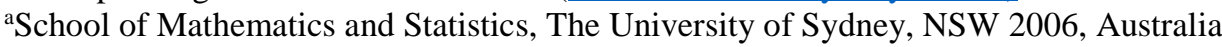

Keywords: tertiary mathematics education, summer school, term-time, fundamental mathematics

\begin{abstract}
In a study from 2008 to 2009, academics at the University of Sydney initiated the gathering and preliminary analysis of qualitative and quantitative evidence, supporting the claim that students undertaking first year mathematics units of study achieve superior learning outcomes, and experience higher overall course satisfaction, by completing units at summer school rather than during term-time. This article includes a follow-up study, focusing on two fundamental mathematics units of study taken by students at the University of Sydney over the period 2007 to 2014. We consider the relative performance of students who failed one or both of these units in term-time and then attempted the unit or units again at the Sydney Summer School. The median increase in numerical grades, in the order of ten to fifteen percentage points, appears to be significant, and often translates, in individual cases, to one or more qualitative leaps upwards, from superficial towards deep learning, in terms of phases in the SOLO taxonomy, or in terms of successful navigation through liminal space, in the theory of threshold concepts.
\end{abstract}

\section{Introduction}

Whilst tertiary tuition delivered or undertaken in 'term-time' may have a general or generic meaning or interpretation within and across tertiary institutions, by contrast with intensive modes of teaching such as summer or winter schools, the relevant terms as they apply to the analysis in this article are defined carefully now, to avoid any ambiguity or confusion. This may assist in facilitating research by others, in making comparisons, or attempting to test or replicate the results of this study, using contrasting modes of teaching in other tertiary institutions. In this article, term-time refers to delivery and assessment of units of study in either of two semesters each year at the University of Sydney, namely, First Semester, from March to June, and Second Semester, from August to November. Each semester comprises thirteen weeks of classes, with a mid-semester break lasting one week, followed by a study week and then a two-week examination period. By contrast, Summer School at the University of Sydney runs through January and February each year, comprising six weeks of classes, a short break, followed by an examination period of several days. Units of study offered at Summer School are, in principle, equivalent to units of study offered in term-time having the same name and course code, in terms of content, aims and learning outcomes, and credit towards relevant degrees. All term-time and Summer School units of study are subject to the same rules, regulations and policies of the University of Sydney.

From 2008 to 2009, a study was undertaken by a number of full-time and casual academic staff at the University of Sydney, and the results published (Easdown et al., 2009), to examine evidence supporting the claim that students undertaking first year mathematics units of study 
achieve superior learning outcomes, and experience higher overall course satisfaction, by completing units at Summer School rather than in term-time. Evidence in that study included quantitative and qualitative survey data and data relating to overall grade performances. In particular, it was found that across four broadly based first year mathematics units of study, students who failed units of study in term-time and repeated them at Summer School had a median increase in numerical grades by between 16.5 and 26 percentage points. One would expect students to improve their performance on a second attempt at a unit. However, for an increase of twenty or more marks, this can represent an improvement from an outright Fail grade to achieving a high Pass or Credit grade. For improvement above the median this can represent an improvement from Fail grades to Distinction or even High Distinction grades. The authors of that study invited other researchers to see if this phenomenon could be confirmed or replicated in other units of study or for other years.

This present study is a response to that invitation and focuses on just two closely related first year mathematics units of study, which we shall refer to as Course A and Course B respectively. Both units of study have an assumed knowledge or background equivalent to HSC Mathematics in New South Wales, Australia. They have been offered for many years, and continue to be offered, both in term-time and at Summer School at the University of Sydney. Course A is offered in First Semester, whilst Course B, which is often regarded as a sequel to and relies on material taught in Course A, is offered in Second Semester in term-time. Both units of study are considered (and subsequently referred to as) fundamental, in the sense that they require a minimal knowledge and understanding of calculus from school (as compared with higher or advanced mathematics units in First Year at the University of Sydney that assume backgrounds equivalent to Extension 1 or Extension 2 HSC Mathematics in New South Wales). Course A includes fundamental techniques in differential and integral calculus in one and several variables, and Course B includes fundamental modelling techniques involving differential and difference equations.

The data analysed below was gathered from records held at the University of Sydney spanning the years 2007-2014 inclusive, well beyond the time-frame considered in the earlier study (Easdown et al., 2009). Though records exist and are available beyond 2014, the authors did not consider using them because of substantial changes in assessment policies and practices implemented at the University of Sydney from 2015. These changes affect the way numerical grades are produced and interpreted from 2015 onwards, rendering it difficult to obtain reliable or rigorous comparisons of data before and after 2015. (It is possible, however, that in a future study, a rigorous comparison could be made for data that is collected only after 2015, and only after the effects of the policy changes have settled down and consistent practices apply to both term-time and Summer School.)

The first author has over thirty years' experience teaching tertiary mathematics at several Australian universities, served as Coordinator of Summer School from 2007 to 2014, and as Director of First Year Studies in the School of Mathematics and Statistics from 2012 to 2014. The second and third authors have taught both Course A and Course B at Summer School and during term-time over the period of this study, the second author as lecturer-in-charge of Course A, and the third author as lecturer-in-charge of Course B. Both the second and third authors have roles at the Mathematics Learning Centre at the University of Sydney, one of the primary roles of which is to assist weaker students, or students at risk, enrolled in these and other first year units of study in mathematics and statistics. 


\section{The SOLO taxonomy and the theory of threshold concepts}

Both the SOLO taxonomy and the theory of threshold concepts provide convenient tools for interpreting grade data related to student learning outcomes reported upon in this article. For the convenience of the reader, these are both briefly summarised in this section, with all relevant terminology mentioned or explained.

The SOLO (Structure of Observed Learning Outcome) taxonomy was devised by Biggs and Collis (1982) as a tool for classifying learning and teaching activities and outcomes, and is useful in practical applications of the theory of constructive alignment and for differentiating between surface and deep learning (see, for example, Biggs \& Tang, 2007). The SOLO taxonomy has been applied to understand and inform processes in learning and teaching mathematics (see, for example, Chick, 1988; Chick, Watson, \& Collis, 1988; Coady \& Pegg, 1994; Coady \& Pegg, 1995; Stillman, 1996; Lian \& Yew, 2012; Caniglia \& Meadows, 2018), in developing innovative assessment practices in primary and secondary school mathematics (see Pegg, 2003), in making international comparisons of primary school mathematics curricula (see Alsaadi, 2001), and also in the process of conducting and developing research in mathematics (see Chick, 1998).

The SOLO taxonomy uses three basic categories to describe the level of a student's understanding or comprehension. In the prestructural phase, a student has not properly grasped or understood anything significant related to the subject matter. The level of cognition could be described as amorphous and without clear identifiable structure or coherence. In the quantitative phases, the student may have grasped or mastered isolated pieces of information or technique, but does not see or understand how these come together. These phases can be broken up into an initial unistructural phase, where a student has successfully mastered just one aspect, followed by the multistructural phase, where the student manages to focus on more than one, and possibly many, aspects. The student is aggregating expertise, though individual items retain, in the mind of the learner, the characteristic of being isolated from one another. In the qualitative phases, the student begins to see how ideas and techniques from the quantitative phases come together to form an integrated whole, where individual parts coordinate, to work together to produce a powerful concept or method. There are two qualitative phases. The relational phase refers to the initial coming together or integration of parts. It marks a critical point or threshold (and see discussion about threshold concepts below), where meaning and significance become apparent and the subject matter transforms. The student shifts position from, previously, being a surface learner to, now, becoming, or having the potential to become, a deep learner and expert. Learning potential may expand rapidly, as the student moves into the highest extended abstract phase: here, integration leads to further conceptualisation, or elevated levels of abstraction and generalisation, giving rise to surprising and spectacular insights, breakthroughs and applications.

The theory of threshold concepts was introduced and developed by Meyer and Land (2003a) (and see also Meyer \& Land, 2005; Land, Cousin, Meyer, \& Davies, 2005; Cousin, 2006), in order to explain and inform processes that lead to successful and deep learning. A threshold concept is a key idea or notion associated with a particular discipline that has transformative and integrative properties, opening up pathways or portals, to new and otherwise inaccessible knowledge and understanding. One hopes to identify threshold moments, when the student's understanding or perception crystallises, empowering the student. In order to move towards and reach such portals, students embark on journeys along pathways that may be problematic, frustrating or troublesome, involving twists and turns, possible backtracking and repetitive 
behaviour, making and recovering from mistakes. Before reaching a particular portal, a student is said to be in liminal space. The educator's principal task is to create or facilitate an environment in which the student is prompted first to move into liminal space (possibly from an initial state referred to as preliminal), and then successfully navigate his or her way through it until the relevant threshold concept is mastered. This can involve a great deal of time and effort. The effect of mastering a threshold concept is so powerful that the changes in the learner's mind become irreversible. The theory is relatively undeveloped in mathematics, though there are some exploratory articles and applications (see Meyer \& Land, 2003b; Easdown, 2007; Worsley \& Bulmer, 2008; Wood et al., 2011; Easdown, 2011a; Easdown, 2011b; Jooganah, 2009; Scheja \& Pettersson, 2010; Pettersson, 2011; Loch \& McLoughlin, 2012; Easdown \& Wood, 2014; Oates, Raeburn, Brideson, \& Dharmasada, 2018; Easdown, Roberts, \& Corran, 2018).

Preliminal and early features of liminal space may correspond roughly to the prestructural and quantitative phases of SOLO. Measures of progress in these phases tend to relate to an accumulation or aggregation of disconnected or isolated skills or pieces of information. The act of reaching the portal associated with a given threshold concept, and then unlocking the power of the underlying ideas or techniques, corresponds roughly to moving into the relational and extended abstract phases of SOLO. Measures of success in the higher phases may be expressed in terms of mastery, fluency and depth of learning.

\section{Methodology}

\section{Selection of data}

Initially, all students were selected, within the period 2007-2014 inclusive, who failed Course A or Course B in term-time and subsequently repeated one or both of these units of study either in term-time or at Summer School. Their performances in other units of study were not taken into consideration. From this population, to ensure that valid comparisons can be made, using legitimate attempts at completing units of study, students were excluded who received a grade of Absent Fail or who did not complete the final examination. This produced two subpopulations: 177 students who repeated the relevant unit of study at Summer School and 332 students who repeated in term-time. Thus, of this entire combined cohort, just over onethird of students chose to repeat the relevant unit of study at Summer School.

Data relating to unit of study completions at Summer School earlier than 2007 were not available. The most recent dataset used for Summer School related to the year 2014, whilst for term-time, it related to 2013. As mentioned in the Introduction, the cut-off at 2014 occurred for a natural reason: substantial changes in assessment policies and practices at the University of Sydney were implemented from 2015, making it then difficult to infer rigorous or meaningful comparisons.

For each student, final numerical grades for the relevant unit of study, Course A or Course B, as appearing in their University of Sydney academic transcript, were recorded, as pairs of results: the first result in the pair being the failing grade in term-time, and the second result in the pair being the subsequent grade achieved after repeating the unit of study either in termtime or at Summer School.

\section{Statistical analysis}

Throughout the analysis below, the median is used as the primary measure of central tendency, since it is less susceptible to influence from outlier scores; it was also the statistic of choice in Easdown et al., (2009). Though data for the complete populations were analysed for the period 
2007-2014, one may also regard these populations as samples from a more abstract population of hypothetical students failing in term-time and repeating either in term-time or at Summer School, and consider the relevant likelihood or expectation of success. For this purpose, the Mann-Whitney test for medians is applied at the 95\% significance level. In the box-andwhisker charts, the blue line represents the median, and is surrounded by a notch giving the corresponding $95 \%$ confidence interval. The mean is indicated by the red line.

Microsoft Excel was used for the storage of the raw data, whilst Wolfram Mathematica was used for all mathematical and statistical analyses.

\section{Results}

By the difference in numerical grades we mean the result of taking away the first failing numerical grade from the numerical grade achieved at the second attempt:

$$
\text { difference in numerical grades }=(\text { grade at second attempt })-(\text { failing grade at previous attempt })
$$

This difference will be positive if and only if the student's grade is higher at the second attempt. Thus, this difference will be negative if the given student failed the given unit of study at the second attempt, achieving an even lower grade. The data are organised into several associated populations or subpopulations:

- $D T T_{\mathrm{A}}$ : the differences in the numerical grades after repeating Course A in term-time, which may be positive or negative (always a whole number between -50 and 100).

- $D T T_{\mathrm{B}}$ : the differences in the numerical grades after repeating Course B in term-time.

- $D T T_{\mathrm{AB}}$ : the union of the previous two populations, that is, the differences in the numerical grades after repeating in term-time, regardless whether for Course A or for Course B.

- $D S S_{\mathrm{A}}$ : the differences in the numerical grades after repeating Course A at Summer School.

- $D S S_{\mathrm{B}}$ : the differences in the numerical grades after repeating Course B at Summer School.

- $D S S_{\mathrm{AB}}$ : the union of the previous two populations, that is, the differences in the numerical grades after repeating at Summer School, regardless whether for Course A or for Course B.

- $F_{\mathrm{TT}}$ : the failing grades of students that subsequently repeated the unit in term-time (always a positive whole number less than 50).

- $F_{\text {Ss: }}$ the failing grades of students that subsequently repeated the unit at Summer School.

Box plots are provided for each of these populations, organised into three figures below, grouped together to facilitate appropriate comparisons:

- Figure 1 compares populations $D T T_{\mathrm{AB}}$ and $D S S_{\mathrm{AB}}$, that is, compares the final mark differences between second attempts taken in term-time and at Summer School, regardless of the unit of study.

- Figure 2 compares populations $F_{\mathrm{TT}}$ and $F_{\mathrm{SS}}$, that is, the initial failing grades of students who go on to repeat in term-time and at Summer School respectively.

- Figure 3 (like Figure 1) compares final mark differences between second attempts taken in term-time and at Summer School, but separating out the data, displaying and comparing $D T T_{\mathrm{A}}$ and $D S S_{\mathrm{A}}$ (for Course A), $D T T_{\mathrm{B}}$ and $D S S_{\mathrm{B}}$ (for Course $\mathrm{B}$ ), in that order. 


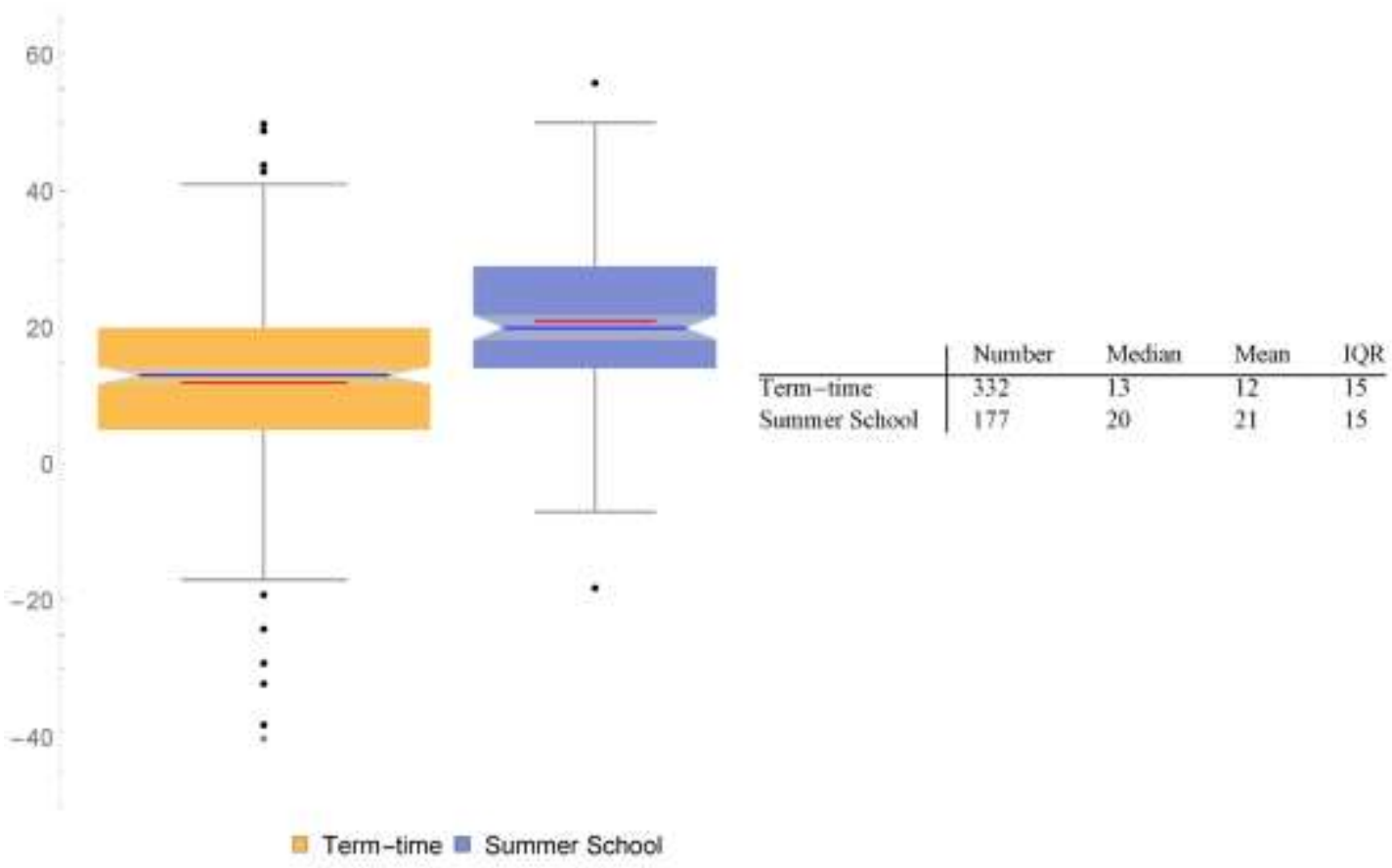

Figure 1: Comparison of the final mark differences between adjacent attempts of students choosing to repeat in Summer School versus term-time.

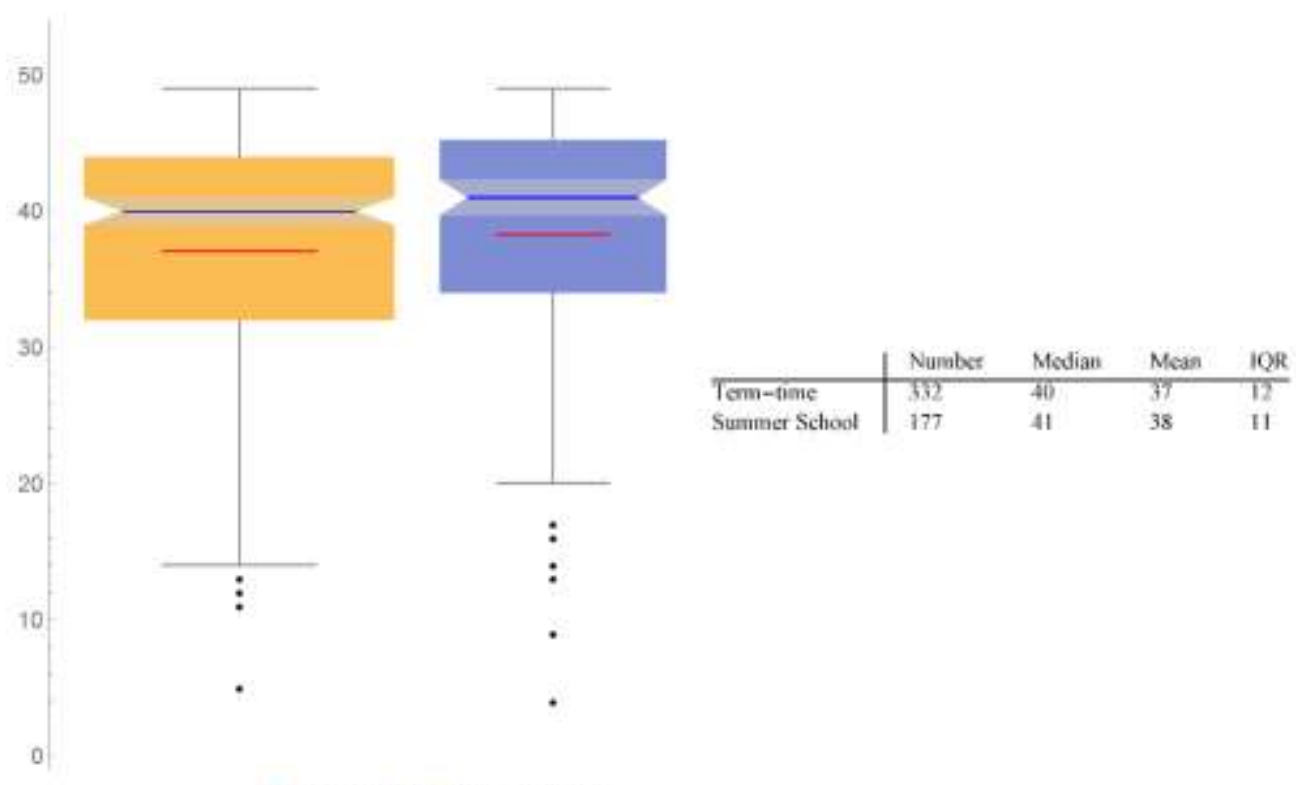

in Term-time a Summer School

Figure 2: Comparison of the (first attempt) final fail marks of students choosing to repeat in Summer School versus term-time. 


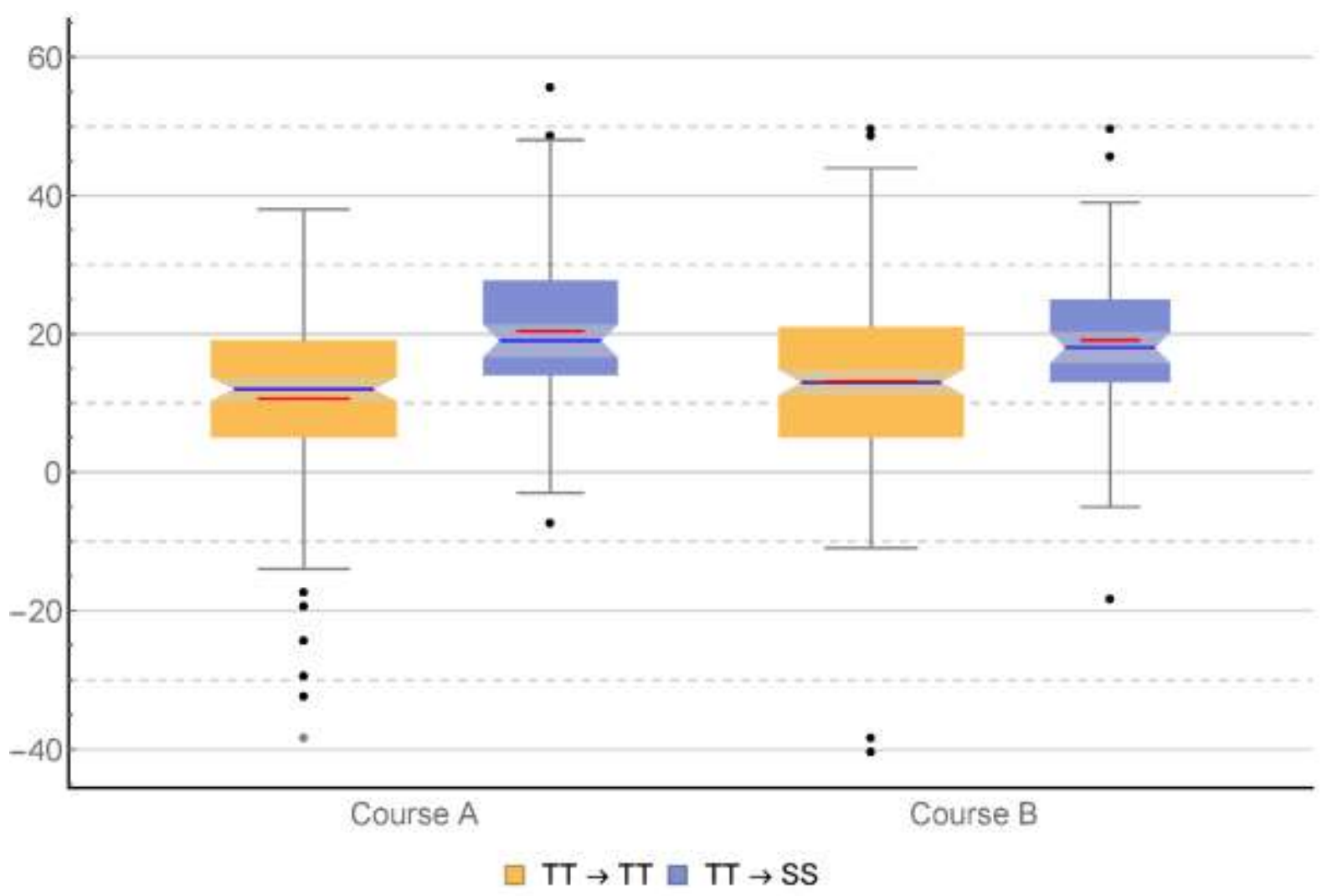

\begin{tabular}{l|lllll} 
& Number & Median & Mean & IQR & Skewness \\
\hline Course A TT $\rightarrow$ TT & 158 & 12 & 11 & 14 & -0.76 \\
Course A TT $\rightarrow$ SS & 83 & 19 & 20 & 14 & 0.43 \\
Course B TT $\rightarrow$ TT & 174 & 13 & 13 & 16 & -0.25 \\
Course B TT $\rightarrow$ SS & 72 & 18 & 19 & 12 & 0.031
\end{tabular}

Figure 3: Comparison of final mark increases for both term-time (TT) and Summer School (SS) repeaters across the two fundamental units of study.

Looking at the tables and box-plots in Figure 1, over the period 2007-2014, the median and arithmetic mean increases in performance, for those repeating Course A and Course B in termtime, are 13 and 12 percentage points respectively. By contrast, the median and arithmetic mean increases, for those repeating Course A and Course B at Summer School, are 20 and 21 percentage points respectively. Therefore, over this period, students repeating these units of study at Summer School achieved an advantage of about 7 (using the median) or about 9 (using the arithmetic mean) percentage points compared with students repeating in term-time. The interquartile ranges remain identical for both populations, with a shift upwards of about 8 percentage points in favour of those repeating at Summer School.

Looking at the tables and box-plots in Figure 2, we can see that the bulk of the first attempt fail grades occur in the range 32-45. The interquartile ranges, first and third quartiles, median and mean are almost the same for both populations, differing by only one percentage point in each case, with the exception of the first quartiles, which differ by two percentage points. The boxplot for those repeating at Summer School is very slightly compressed and elevated compared with the box-plot for those repeating in term-time, with overlapping notches (95\% confidence intervals). 
In Figure 3, the data that led to the box-plots for Figure 1 are separated, to provide box-plot comparisons for each of Course A and Course B. For Course A, the interquartile ranges remain the same, moving up about 8 percentage points in favour of repeating at Summer School, with corresponding increases of 7 and 9 percentage points for the median and arithmetic mean respectively. For Course B, the interquartile range contracts by 4 percentage points from repeating in term-time to repeating at Summer School, though the median and arithmetic means increase by 5 and 6 percentage points respectively in favour of repeating at Summer School. In both cases, there is no overlap in the notches (95\% confidence intervals) of the box-plots for each pair of courses, so the increases in favour of repeating at Summer School may be regarded as significant for both courses. Interpretations of this significance, and also possible reasons or explanations, are discussed in the following section.

\section{Discussion}

In order to interpret these results, it is necessary first to be aware of the grade ranges used in these units of study at the University of Sydney, and how these translate into a description of the intended quality of performance and breadth and depth of learning outcomes. Passing grades of 50-64 are achieved by students who appear to exhibit at least routine knowledge and understanding across a spectrum of topics and important ideas in the course. Grades in the range 50-54 are marginal, and students in this range may be regarded as remaining at risk, and should exercise caution, if they intend to pursue further studies in mathematics on which the unit of study relies. Failing grades below 50 are regarded as unsatisfactory, and evidence of substantial weaknesses or gaps in routine knowledge or understanding. Typically, a student achieving a failing grade appears to have remained in the prestructural phase, or possibly in isolated unistructural or weak multistructural phases of the SOLO taxonomy; he or she may lack confidence, or the ability to solve problems that may be regarded as routine or straightforward, or may lack rudimentary mathematical communication skills. The student who has moved across the passing boundary of 50, however, appears to have demonstrated at least routine competencies, possibly still within the unistructural and multistructural phases of SOLO, but with evidence of some solid foundation upon which to build. Students in the failing range may typically remain in preliminal space or only make small steps in liminal space towards learning the relevant threshold concepts. A student in the passing range may still reside in liminal space, but has the potential to work independently and progress towards the relevant portals.

Credit grades of 65-74 are achieved by students who appear to be moving into the relational phase of SOLO, integrating ideas and techniques from the multistructural phase, and demonstrating ability to solve a diversity of problems with increasing degrees of sophistication and to successfully communicate mathematical ideas. To at least some significant extent, the understanding of the student achieving a credit grade may be being transformed by one or more relevant threshold concepts, and he or she may be on a pathway towards becoming a deep learner.

Distinction grades of 75-84 are achieved by students who appear to have made excellent progress, almost certainly in relational phases, but possibly also in extended abstract phases of SOLO. These students may have passed through portals of relevant threshold concepts, been transformed by the experience and shown strong and consistent evidence of deep learning and excellent mathematical communication skills. 
High Distinction grades of 85-100 are awarded to students who appear to have achieved mastery or close to complete mastery of all or most of the relevant topics. These students may be functioning naturally and creatively in the relational and extended abstract phases of SOLO and may be regarded as being on the pathway to becoming experts in the field, with the potential to undertake honours or research degrees.

The earlier results may now be interpreted in these descriptive contexts. From Figure 2, the bulk of the fail marks at the first attempt occur in the range 32-45. For students repeating in term-time, the range is 32-44, and the median increase in their performance of 13 marks (see Figure 1) places those students typically in the range 45-57. The lower end of this range is still failing, and the upper end is just above what is regarded as a marginal passing performance. These students appear to remain trapped in preliminal or liminal space and almost exclusively within the quantitative phases of SOLO. Their learning appears to remain, on the whole, fragile, fragmented and superficial. Beyond the median, the boxplot indicates that some of these students achieve a Credit or Distinction on the second attempt, but these are relatively rare and isolated. By contrast, there is a significant tail below the median, comprising students who appear to be trapped in a spiral or syndrome of repeated failure in mathematics.

Students repeating at Summer School have a similar range of initial failing grades (34-45, see Figure 2). By contrast, however, the median increase in performance of 20 marks (see Figure 1) places those students typically within the range 54-65. The lower end of this range is at the top of a marginal passing grade. Almost all of this range extends from strong passing grades up to the threshold for credit grades. These students, by contrast with the other cohort mentioned in the previous paragraph, do not appear to remain trapped in preliminal space or in the prestructural phases of SOLO. They appear to be achieving solid or strong results in the unistructural and multistructural phases. Some of them exhibit evidence of successful learning activities in the relational phase of SOLO. Above the median, there are significant numbers of these students who appear to be operating in the qualitative phases of SOLO and achieving Credits, Distinctions and some High Distinctions. These students evidently drastically improve their level of understanding. They no longer appear to be floundering in preliminal or liminal space; they have exhibited potential for deep learning and successful navigation through to and beyond the relevant threshold concepts. Below the median, very few of these students move backwards and fail on their second attempt.

In summary, the data from Figures 1 and 2 provide evidence to suggest that failing students repeating at Summer School appear to gain much more momentum as they move through the passing grade barriers towards the higher grades. They appear to shake off liminal or preliminal confusion or mathematical inhibition and move into the spectrum of deep and substantial learning. By contrast, failing students who repeat in term-time either do not succeed in passing again, or move through the passing grade barrier with little momentum and tend to remain in liminal space and within the spectrum of surface learning.

Separate data appear in Figure 3 for Courses A and B respectively. The increase in successful performance by students repeating at Summer School appears in both courses, but slightly more markedly in Course A, by about 2 percentage points in the final grades, than in Course B. As mentioned in the Introduction, these courses are in principle intended to be equivalent to the corresponding courses in term-time, in terms of content, aims and learning outcomes. The Summer School lecturers and instructors for Course B, over the period 2007-2014, consistently used the same teaching materials, formats, exercise sheets, quizzes and equivalent exam questions, in terms of content and style, as term-time. The Summer School lecturer for Course 
A also made use of the same materials as term-time, but introduced and examined some new topics, and consistently used more difficult or novel assessment tasks and exercises. One might expect then that students who failed Course A in term-time and attempted it again at Summer School in this period might be disadvantaged. The data suggest otherwise, that, in fact, something about the intensive mode of teaching and learning appears to improve the quality of their learning. In light of this, the data from Figure 3 could tentatively suggest that making a course at Summer School more challenging or rigorous than term-time might create even more benefits or value for students and their learning. The data displayed in Figures 1 and 3 provide evidence to suggest that there is a real and tangible positive 'Summer School effect'.

Some particular aspects or features of Summer School are now discussed in more detail, which might shed some light on why this phenomenon occurs and prompt further research. In this study we have found it useful to interpret differences in performances descriptively in terms of phases of the SOLO taxonomy or in positioning in liminal or preliminal space or relative to portals in the theory of threshold concepts. The next stage in future research might be to aim towards understanding the underlying dynamics, for example, in theories of intelligent learning and goal-directed actions (see Skemp, 1987), or in terms of some variant of a presage-productprocess model of teaching and learning (see Biggs, 1993). One might, for example, try to identify features of either mode of learning and teaching that promote or inhibit the successful development in the mind of the learner of mathematical concepts and schemas (in the sense of Skemp). One could investigate the creative use of intuitive and reflective intelligence, identifying appropriate or optimal interpersonal relations between student and instructor, and tease out other influential factors related to motivation, attitudes and emotion. Daniel (2000), in her survey article involving many varied disciplines, reported on a range of related factors that distinguish the learning environments of time-shortened courses from more traditional term-time courses. However, she decried the lack of rigour in research methodologies that lead to accurate or meaningful comparisons of learning outcomes. Gordon and Nicholas (2010) report on factors influencing the success of short mathematics bridging courses and how they might ameliorate students' difficulties with mathematics in transition to university (see also the comparative study by Poladian \& Nicholas, 2014). They encouraged further research and discussion that might stimulate active debate and reflection about associated pedagogy.

\section{Desperation to pass and catch up}

A significant proportion of students that attend Summer School are those that have failed mathematics units during term-time. The successful completion of twelve credit points of mathematics or statistics is presently a compulsory requirement to obtain a science degree at the University of Sydney. Summer School therefore provides a convenient and natural means by which failing students can catch up and avoid delay in the completion of their degree. The fees for units of study at Summer School were significantly more expensive than in term-time. Though issues about fees were rarely mentioned by students in unit of study surveys taken over the period 2007-2014, it is possible that the incentive not to waste time catching up, and doing so at considerable personal expense, including forgoing holidays or opportunities to work, may be strong motivating factors. The fact that much of the student cohort has the same or similar failing background, and commonality of purpose, may also remove stigma attached to failing and help to make such students feel more comfortable participating in class and interacting with other students. 


\section{Superior teaching and learning environments}

\section{Smaller class sizes}

Typically, in the period 2007-2014, lecture class sizes in Summer School ranged around approximately 30-50 students, whilst tutorial class sizes ranged approximately 10-15 students. By contrast, equivalent term-time courses had approximately 250-350 students per lecture stream, with multiple lecture streams, and 20-30 students per tutorial. With significantly smaller class sizes in Summer School, each student has a greater opportunity to become engaged and interact with teaching staff. This 'close-knit' environment is more likely to create a learning experience of high quality, and more suited to guiding and mentoring students with previously poor attitudes or study habits.

\section{Teaching staff and flexible block teaching}

Lecturers and tutors at Summer School are typically selected from a pool of young, enthusiastic and dedicated postgraduate students, all willing to give up several weeks of their break between semesters to teach over summer. Many of them have had direct teaching experience working with students with weak or problematic backgrounds in term-time. Some of them work for the Mathematics Learning Centre or assist in teaching the mathematics bridging courses, having a natural affinity for helping students at risk. The Summer School lecturers almost always give integrated lectures and tutorials, typically in blocks of three hours; thus, they get to know the students very well. It is easier then to create a friendly, accessible and supportive learning environment. By contrast, lecturers in term-time are usually appointed from ongoing permanent academic staff, who may not have any particular expertise or special interest in teaching or working with students from the weaker end of the mathematical spectrum, and indeed may have mathematical research as their primary academic focus. Lectures in term-time are typically delivered as single hours on different days and separated from tutorials. Lecturers in term-time also sometimes do not give tutorials, so they can be more detached from students and be less aware of individuals, their needs and aspirations. Lecturers at Summer School are also given greater autonomy and flexibility to experiment with teaching and learning techniques, to adapt their methods to the needs of individual students, and to create superior alignment of aims, objectives, learning activities and assessment tasks (facilitating constructive alignment, in the sense of Biggs and Tang (2007), where students are more able to react and construct their own learning). Teaching in term-time tends to be more rigid and regulated, less innovative and less able to respond directly to the needs of individuals.

\section{Minimal distractions, maximum focus}

During term-time, students are typically taking a full or close to full load, including four or five units of study. Additionally, many students participate in an array of extra-curricular activities and social events associated with the University. By contrast, the Summer School environment is quiet and subdued, and students are typically focusing on just one or two units of study. Though these units are delivered and assessed in approximately half the amount of time taken by corresponding units in term-time, there is greater immediacy in the sequence of topics, and less opportunity for concentration and effort to be dispersed across multiple activities and commitments. Material remains fresh in the minds of students and is followed up and reinforced by timely completion of assessment tasks. The faster pace at Summer School, provided it is not overwhelming, may become an advantage in terms of focus, retention and sharper learning in context. By contrast, in term-time, students' concentration, retention and focus may be broken, interrupted or diluted by the longer session, punctuated by public holidays and teaching breaks, followed by a long and drawn-out examination period. 


\section{Value for money}

In the current competitive tertiary education climate in Australia, students may be looking for 'value for money' in their degree programmes. If students are paying more, then one would expect that they will naturally be more demanding of value. One might argue that Summer School over this period (2007-2014) was no more than a 'premium product' with a higher price tag. However, as mentioned earlier, issues relating to fees were rarely mentioned in unit of study evaluations at Summer School. Further, all of the features and apparent advantages of Summer School mentioned above add little or no extra cost to the University: the teaching staff are casual (not permanent, so there are no extra overheads) and the organisation of classes and materials are primarily matters of intelligent planning and logistics; only the smaller tutorial sizes add additional costs, but these are marginal and insignificant compared to the income produced from student fees.

One may ask whether intensive-mode delivery (IMD) formats, such as Summer School, are a form of 'commodification of education' as described in Davies (2006), where the author questions the true motives of tertiary educational institutions that are becoming more like 'corporate entities'. Is IMD concerned with the quality of learning and teaching, or is it simply conceived and encouraged as another lucrative method of raising revenue, in order to subsidise other activities (such as research) of tertiary institutions? With regard to the University of Sydney, explicit reference to teaching programs in Summer and Winter is made in its Strategic Plan 2016-2020: Initiative 2 of Strategy 5 (Transform the learning experience) is concerned with creating "contemporary environments that enable flexible and interactive learning" over Summer and Winter breaks, and providing "a diversity of educational experience for students, as well as teaching experience for staff, which can be especially engaging". Certainly, the features and advantages of Summer School described above are consistent with the spirit and intent of the Strategic Plan. Summer School instructors are not only experienced and innovative teachers, but they display empathy and enthusiasm towards struggling students. Regardless of answers to questions about revenue and motives, the results of this study clearly support the claim investigated in Easdown et al., (2009) that the quality of learning outcomes improves significantly if students undertake units of study at Summer School rather than term-time.

\section{Conclusions}

The analysis of grade data from fail-repeating students in closely aligned fundamental mathematics units of study, over the period 2007-2014, supports the conclusion that students are more likely to succeed by repeating units of study at Summer School rather than in termtime. The median increase in numerical grades, in the order of ten to fifteen percentage points between the two modes of study, appears to be significant. The level of success suggests that, with regard to fundamental mathematics, failing students that repeat at Summer School are more likely to move out of preliminal or liminal space (with regard to the theory of threshold concepts) or prestructural phases (with regard to the SOLO taxonomy), master relevant threshold concepts and move beyond the quantitative phases towards or into the qualitative relational and extended abstract phases of learning. By contrast, the data suggest that failing students who repeat in term-time are more likely either to fail again or obtain marginal passing grades that reflect relatively superficial learning outcomes.

Contrasting features of learning and teaching both in term-time and at Summer School were discussed. They may help to explain these results or put them in context, namely, in relation to students' motivation to succeed, the differences in class sizes, the contrasting qualities and attributes of teaching staff, the ways in which classes and teaching materials are organised, the 
substantially different time periods over which the courses are delivered, and effects on student focus and concentration. Issues related to fees and the commercialisation of education have been raised, but there is insufficient evidence, at this stage, to claim that these issues influence the underlying dynamics in the differences in the quality of learning outcomes.

The conclusions of this study support the claim made in Easdown et al., (2009) that students undertaking first year units of study achieve superior learning outcomes, and experience higher overall course satisfaction, by completing units at Summer School rather than during termtime. These results may, for example, inform course advisers when dealing with students at risk or with weak or problematic backgrounds in mathematics. It is possible, also, that heightened awareness of some of the features of learning and teaching at Summer School, and the benefits that may flow from them, might inform more effective or improved practices in term-time delivery of mathematics courses.

\section{Acknowledgments}

This study is part of a research project (Reference Number 07-2009/11959) approved by the Human Research Ethics Committee of the University of Sydney. The authors would particularly like to thank Jackie Nicholas, Head (now retired), Mathematics Learning Centre, and staff and students of the School of Mathematics and Statistics, University of Sydney, for their assistance in completing this study.

\section{References}

Alsaadi, A. (2011). A comparison of primary mathematics curriculum in England and Qatar: The SOLO taxonomy. Proceedings of the British Society for Research into Learning Mathematics, 21(3). [Online: http://www.bsrlm.org.uk/wp-content/uploads/2016/02/BSRLM-IP-21-3-1.pdf].

Biggs, J. B. (1993). From theory to practice: A cognitive systems approach. Higher Education and Research and Development, 12, 73-86.

Biggs, J.B. \& Collis, K. (1982). Evaluating the quality of learning: the SOLO taxonomy. New York: Academic Press.

Biggs, J.B. \& Tang, C. (2007). Teaching for quality learning at university, $3^{\text {rd }}$ Edition. New York: Society for Research into Higher Education \& Open University Press.

Caniglia, J., \& Meadows, M. (2018). An application of the SOLO taxonomy to classify strategies used by preservice teachers to solve "one question problems". Australian Journal of Mathematics Education, 43(9), 7589.

Chick, H.L. (1988). Student responses to a polynomial problem in the light of the SOLO taxonomy. Australian Senior Mathematics Journal, 2, 91-110.

Chick, H.L. (1998). Cognition in the formal modes: Research mathematics and the SOLO taxonomy. Mathematics Education Research Journal, 10(2), 4-26.

Chick, H. L., Watson, J. M. \& Collis, K. F. (1988). Using the SOLO taxonomy for error analysis in mathematics. Research in Mathematics Education in Australia, May-June 1988, 34-47.

Coady, C., \& Pegg, J. (1994). Tertiary students' understanding of second order relationships in function notation. In G. Bell, B. Wright, N. Leeson \& J. Geake (Eds.), Challenges in mathematics education: Constraints on construction. Proceedings of the 17th annual conference of the Mathematics Education Research Group of Australasia, Vol. 1, (pp. 179-186). Lismore, NSW: MERGA.

Coady, C., \& Pegg, J. (1995). Students' use of second-order relationships in algebra. In B. Atweh \& S. Flavel (Eds.), Galtha. Proceedings of the 18th annual conference of the Mathematics Education Research Group of Australasia, (pp. 189-194). Darwin, NT: MERGA.

Cousin, G. (2006). An introduction to threshold concepts. Planet, 4-5.

Daniel, E. L. (2000). A review of time-shortened courses across disciplines. College Student Journal, 34(2).

Davies, W. M. (2006). Intensive teaching formats: A review. Issues in Educational Research, 16(1), 1-20.

Easdown, D. (2007). The role of proof in mathematics teaching and the Plateau Principle. In Alexandra Hugman, Ian Johnston \& Mary Peat (Eds.), Proceedings of the Assessment in Science Teaching and Learning Symposium. University of Sydney: Uniserve Science.

Easdown, D. (2011a). Transforming practice using threshold concepts. ALTC Professional Development Workshop. University of Wollongong, September 29-30, 2011. [online: http://www.austms.org.au/ALTC+Workshop+2011]. 
Easdown, D. (2011b). Excursions to and from semantic oblivion. In John Hannah \& Mike Thomas (Eds.), Proceedings of Volcanic Delta 2011, The Eighth Southern Hemisphere Conference on the Teaching and Learning of Undergraduate Mathematics and Statistics. University of Canterbury.

Easdown, D., Ougrinovskaia, A., Saunders, N., Warren, D., Ancev, T., Bishop, T., \& Mansfield, S. (2009). Learning and teaching in summer: Is it better and why? In: Hugman, A. (Ed.), Proceedings of the Uniserve Science Conference Motivating Science Undergraduates: Ideas and Interventions (p: 24-29). The University of Sydney.

Easdown, D., Roberts, B., \& Corran, K. (2018). A novel approach to mathematics examination design and marking. In M. Dullius et al. (Eds.), Proceedings of the 11th Southern Hemisphere Conference on the Teaching and Learning of Undergraduate Mathematics and Statistics (p. 32-48). Univates, Lajeado, Brazil.

Easdown, D., \& Wood, L. (2014). Novel threshold concepts in the mathematical sciences. In C. O'Mahony, A. Buchanan, M. Rourke \& B. Higgs (Eds.), Proceedings of the National Academy's Sixth Annual Conference and the Fourth Biennial Threshold Concepts Conference, Threshold Concepts: From personal practice to communities of practice, (p. 44-50). NAIRTL (Irish National Academy for Integration of Research, Teaching and Learning), Cork, Ireland.

Gordon, S., \& Nicholas, J. (2010). Teachers' reflections on the challenges of teaching mathematics bridging courses. In M. Sharma (Ed.), Proceedings of the $16^{\text {th }}$ UniServe Science Annual Conference, (pp 35-40). University of Sydney: UniServe Science.

Jooganah, K. (2009). Proof as a threshold concept for university mathematics: An exploration of student identity and transition. British Education Research Association Annual Conference. University of Manchester.

Land, R., Cousin, G., Meyer, J.H.F. \& Davies, P. (2005). Threshold concepts and troublesome knowledge (3): Implications for course design and evaluation. In C. Rust, (Ed.), Improving Student Learning - equality and diversity. Oxford: OCSLD.

Lian, L.H., \& Yew, W.T. (2012). Assessing algebraic solving ability: a theoretical framework. International Education Studies 5(6), 177-188.

Loch, B., \& McLoughlin, C. (2012). Teaching threshold concepts in engineering mathematics using

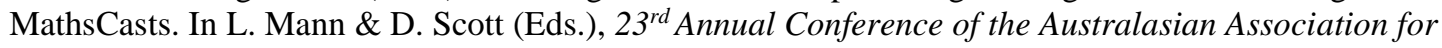
Engineering Education (1079-1086). Profession of Engineering Education: Advancing Teaching, Research and Careers. Engineers Australia, Melbourne, Victoria.

Meyer, J.H.F., \& Land, R. (2003a). Threshold concepts and troublesome knowledge - linkages to ways of thinking and practising. In C. Rust (Ed.), Improving Student Learning - Ten Years On. Oxford: OCSLD.

Meyer, J.H.F., \& Land, R. (2003b). Threshold concepts and troublesome knowledge - linkages to ways of thinking and practising within the disciplines. ETL Occasional Report 4, May 2003. ETL Project, Universities of Edinburgh, Coventry and Durham. [online: http://www.etl.tla.ed.ac.uk/docs/ETLreport4.pdf].

Meyer, J.H.F., \& Land, R. (2005). Threshold concepts and troublesome knowledge (2): Epistemological considerations and a conceptual framework for teaching and learning. Higher Education 49(3), 373-388.

Oates, G., Raeburn, R., Brideson, M., \& Dharmasada, K. (2018). Understanding of limits and differentiation as threshold concepts in a first-year mathematics course. In M. Dullius et al. (Eds.), Proceedings of the 11th Southern Hemisphere Conference on the Teaching and Learning of Undergraduate Mathematics and Statistics (108-120). Univates, Lajeado, Brazil.

Pegg, J. (2003). Assessment in mathematics: A developmental approach. In J.M. Royer (Ed.), Advances in Cognition and Instruction (pp. 227-259). New York: Information Age Publishing Inc.

Pettersson, K. (2011). The threshold concept of a function - A case study of a student's development of her understanding. Stockholm University. [online: http://www.mai.liu.se/SMDF/madif8/Pettersson.pdf].

Poladian, L., \& Nicholas, J. (2013). Mathematics bridging courses and success in first year calculus. In D. King, B. Loch \& L. Rylands (Eds.), Proceedings of the 9th DELTA Conference on the Teaching and Learning of Undergraduate Mathematics and Statistics (pp. 150-159). Melbourne, Australia: University of Western Sydney.

Scheja, M., \& Pettersson, K. (2010). Transformations and contextualisation: Conceptualising students' conceptual understandings of threshold concepts in calculus. Higher Education, 59, 221-241.

Skemp, R. R. (2012). The psychology of learning mathematics: Expanded American edition. New York: Routledge.

Stillman, G. (1996). Mathematical processing and cognitive demand in problem solving. Mathematics Education Research Journal, 8, 174-197.

Wood, L., Vu, V., Bower, M., Brown, N.R., Skalicky, J.L., Donovan, D., Loch, B., Joshi, N., \& Bloom, W. (2011). Professional development for teaching in higher education. International Journal of Mathematical Education in Science and Technology, 42(7), 997-1009.

Worsley, S., Bulmer, M., \& O’Brien, M. (2008). Threshold concepts and troublesome knowledge in a secondlevel mathematics course. In A. Hugman \& K. Placing (Eds.), Symposium proceedings: Visualisation and concept development, (pp. 139-144). The University of Sydney: UniServe Science. 